\title{
AKUSTYCZNY ASPEKT ZASTOSOWANIA BLACHY KORTENOWEJ W EUROPEJSKIM CENTRUM SOLIDARNOŚCI W GDAŃSKU
}

DOI: 10.37660/integr.2020.6.2.3

\section{WPROWADZENIE}

uropejskie Centrum Solidarności (ECS) w Gdańsku zostało ołwarte w roku $2014[3,7]$. Bryła i wnętrza budynku nawiązuja do niedawnej przeszłości tej części miasta, wydzielonej z terenu nadal funkcjonującej Stoczni Gdańskiej. Dominującym elementem architektury ESC sq odchylone od pionu ściany konstrukcyjne, pokryte blacha kortenowa (rys. 1). Podkreśla to symboliczna wymowę obiektu, z jej odniesieniem do wydarzeń z najnowszej historii tej części Europy [12]. Zgodnie z tą inspiracja nie tylko wyglad elewacji i wnętrz, ale także akustyka pomieszczeń ECS nawiq̨zuje do atmosfery wielkich wnętrz przemysłowych.

Celem pracy jest przedstawienie akustycznych aspektów użytkowania pomieszczeń uformowanych z wykorzystaniem takich środków wyrazu architektonicznego.

\section{BLACHA KORTENOWA JAKO MATERIAK WYKOŃCZENIOWY}

Stal kortenowa (oryginalna nazwa COR-TEN) jest stopem o celowo wytworzonej warstwie korozyjnej, zastępującej ochronną powłokę malarska. Uzyskuje się ja przez użycie dodatków stopowych, nadajacych stali pożądane własności metalurgiczne i formujacych sama warstwę korozyjna ( $P$, $\mathrm{Cu}, \mathrm{Cr}, \mathrm{Ni}, \mathrm{Si}, \mathrm{Mo}, \mathrm{Ti}, \mathrm{V})$. Prace nad wytworzeniem stali kortenowej rozpoczęły się w roku 1933, zaś do prakłycznych zastosowań weszła ona $w$ roku 1959 [17].

W swoich podstawowych zastosowaniach stal kortenowa jest materiałem konstrukcyjnym. W postaci blachy jest ona Używana stosunkowo rzadko, głównie ze względu na swój specyficzny walor dekoracyjny. W realizacjach architektonicznych blacha kortenowa jest stosowana głównie

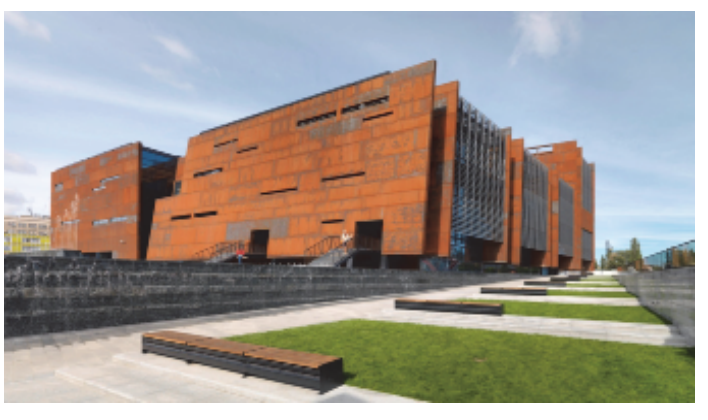

Rys. 1. Fasada południowa ECS, ze ścianami konstrukcyjnymi odchylonymi od pionu o 6,50, w całości pokrytymi płyłami corten o grubości $5 \mathrm{~mm}$ (fot. Wojciech Kryński)

Fig. 1. The south façade of the ECS, with the structural walls deviated from the vertical by $6,5^{\circ}$,entirely covered with corten plates $5 \mathrm{~mm}$ thick (photo by Wojciech Kryński) 
jako pokrycie elewacji budynków biurowych, handlowych, obiektów kultury itp., a także w realizacjach o charakterze monumentalnym, jak pomniki, rzeźby lub inne instalacje na wolnym powietrzu. Szczególna cecha materiału jest ok. 3-letni okres naturalnego stabilizowania się właściwości fizykochemicznych powłoki korozyjnej. Jest to związane ze zmiana jej koloru, a także z pyleniem i osiadaniem rdzawego nalotu na powierzchni gruntu [1 1]. Z tego powodu stal kortenowa jest stosowana głównie na wolnym powietrzu [6, 10, 14]. Ze względu na możliwość pylenia użycie blachy kortenowej w pomieszczeniach wymaga ustabilizowania powłoki korozyjnej, np. przez natrysk cienkiej warstwy lakieru bezbarwnego.

Zastosowanie blachy kortenowej w pomieszczeniach ma miejsce w nielicznych przypadkach [5]. W niniejszej publikacji opisano jej użycie w największych pomieszczeniach ECS, tj. w ogrodzie zimowym i w sali widowiskowej, wraz z wpływem tego materiału na ich akustykę. Blacha kortenowa jest materiałem wykończeniowym dominującym także w innych pomieszczeniach ECS (hol wejściowy, foyer, korytarze). Uzasadnieniem dla takiego rozwiązania jest nawiązanie do jednolitości wykończenia elewacji i wnętrz, charakterystycznej dla wielkich obiektów przemysłowych.

\section{ZASTOSOWANIE BLACHY KORTENOWEJ WE WNĘTRZACH ECS}

We wnętrzach ECS użyto blachy o grubości 1 mm, umocowanej do stalowego stelażu, co sprawia, że jej współczynnik pochłaniania dźwięku jesł porównywalny ze współczynnikiem pochłaniania dźwięku tynku $\left(a_{w} \approx 0,05\right)$. Prowadzi to do dużej pogłosowości i małego rozproszenia dźwięku, co jest charakłerystyczne dla hal przemysłowych. Efekty te sa złagodzone przez zastosowanie w górnych partiach pomieszczeń siatki ciagnionej z blachy kortenowej oraz blachy kortenowej perforowanej, odsuniętej od betonowej ściany, z wypełnieniem pustki wełna mineralna. Przy zachowaniu jednolitości materiałowej wnętrza łagodzi to duża pogłosowość, co kieruje słuchowe odczucia użytkowników od oczekiwanej industrialnej monumentalności ku akustycznej neutralności pomieszczeń użytku publicznego.

\section{Ogród zimowy}

Ogród zimowy skupia wokół siebie najważniejsze funkcje ECS, którymi sa wystawy stałe i czasowe, czytelnie z bibliotekami, biura itp. Sa one dostępne bezpośrednio lub poprzez szerokie korytarze, antresole ze schodami ruchomymi oraz wewnętrzne szklane fasady i otwory okienne. Dzięki temu bryła ogrodu zimowego jest w dużym stopniu rozczłonkowana,

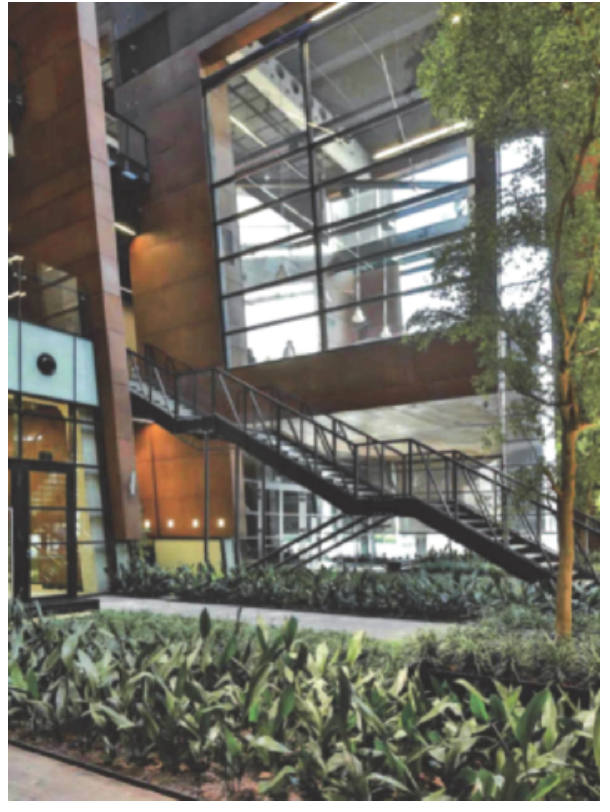

Rys. 2. ECS, ogród zimowy (fot. Bartosz Makowski)

Fig. 2. The ECS, winter garden (photo by Bartosz Makowski) 
co wraz z dużymi zgrupowaniami roślinności rozprasza i pochłania dźwięk, istotnie ograniczając pogłos (rys. 2).

Dane liczbowe ogrodu zimowego:

- długość $\times$ szerokość $\times$ wysokość: ok. $30 \times 30 \times 22 \mathrm{~m}$,

- powierzchnia: $885 \mathrm{~m}^{2}$,

- kubatura, w tym przestrzenie akustycznie sprzężone: $19400 \mathrm{~m}^{2}$,

- powierzchnia blachy kortenowej: ok. $2200 \mathrm{~m}^{2}$,

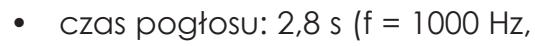
sala pusta, rys. 3).

\section{Sala wielofunkcyjna}

Sala wielofunkcyjna jest poku głównym środkiem kreowania architektury wnętrza sali sa odchylone od pionu ściany boczne, w całości pokryte blacha kortenowa. Zgodnie z przyjęta formuła hali przemysłowej, ściany boczne sa dużymi jednoelementowymi płaszczyznami. Sprzyja to powstawaniu echa trzepoczacego, polegajacego na wielokrotnym odbiciu dźwięku między równoległymi ścianami, co jest akustycznie niekorzystne. $W$ pomieszczeniach o omawianej formie zjawisko to może powstać w obszarze estrady o równoległych, mocno oddalonych od siebie ścianach bocznych, gdzie może być słyszalne dla wykonawców. W przypadku jednak, gdy ściany sa tak znacznie odchylone od pionu, strefa formowania się echa trzepoczacego jest przesunięta ponad estradę, mocno zmniejszajac stopień jego odczuwania (rys. 4).
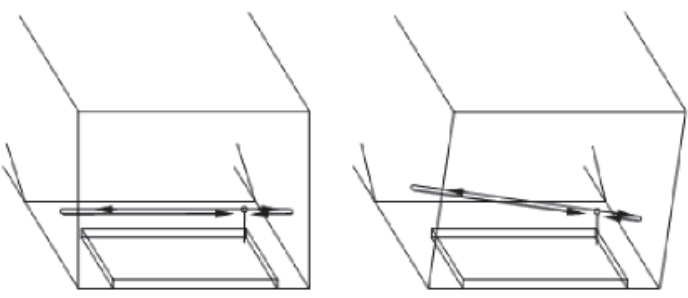

Rys.4. Przesunięcie strefy powstawania echa trzepoczacego (po lewej) powyżej poziomu głów wykonawców w związku z odchyleniem ścian bocznych od pionu o 6,5 $5^{\circ}$ po prawej-opracowanie własne).

Fig. 4. Shift of the zone of forming the flutter echo (left) above the level of the performers heads due to the deviation of the side walls from the vertical (right - own study)

Powstawanie echa trzepoczacego opiera się na geometrycznym modelu propagacji dźwięku w pomieszczeniu. W modelu zakłada się, że przeszkoda odbijajaca dźwięk, w tym przypadku ściana boczna, jest duża w stosunku do długości fali. Można to zapisać jako I $\geq \mathrm{K} \lambda$, gdzie $\lambda$ jest długościa fali, I jest wymiarem przeszkody, a $K$ jest współczynnikiem zależnym od stosunku energii odbitej w sposób zwierciadlany do energii rozproszonej.

W literaturze wybór współczynnika $K$ nie jest wolny od arbitralności. Można spotkać wartości K zarówno większe niż 1, jak i mniejsze (np. K = 1 [1], K = 1/2 [4] 
lub nawet $K=1 / 3$ [9]). W rozpatrywanym przypadku echo trzepoczace powstaje przy długościach fal krótszych niż $\lambda \leq I / K$ lub, równoważnie, w zakresie częstotliwości $\mathrm{f} \geq \mathrm{Kc} / \mathrm{l}$, gdzie c jest prędkością dźwięku w powietrzu, $\mathrm{c}=340 \mathrm{~m} / \mathrm{s}$. Jeśli się przyjmie $\mathrm{K}=4[2,8]$, a wymiary ścian bocznych wynosza co najmniej $5 \times 5 \mathrm{~m}$, zjawiska powstawania echa trzepoczącego pokazanego na rysunku 4 można się spodziewać przy częstotliwościach dźwięku f $\geq 272 \mathrm{~Hz}$.

\section{TESTY AKUSTYCZNE}

Dla zbadania podatności sali na powstawanie echa trzepoczacego, w trakcie prac wykończeniowych przeprowadzono eksperyment akustyczny. Polegał on na słuchowej ocenie słopnia słyszalności echa przy różnych konfiguracjach materiału dźwiękochłonnego doraźnie układanego na ścianach bocznych (rys. 5). Podczas badań porównywano słyszalność echa przy usytuowaniu słuchacza w centralnej części i na skraju estrady, w obecności i bez materiały dźwiękochłonnego. Źródłem dźwięku był wystrzał z pistoletu startowego.

Stwierdzono, że pochylenie ścian jest wystarczajacym krokiem zaradczym, przesuwającym obszar formowania się echa trzepoczącego ponad obszar przebywania wykonawców na estradzie, czyniac echo niesłyszalnym. Dzięki temu uniknięto konieczności wyłłumienia ścian, zwłaszcza ich dolnych partii dobrze widocznych z widowni, co naruszyłoby wizualne nawiązanie do przemysłowego charakteru wnętrza (rys. 6).

Dane liczbowe sali:
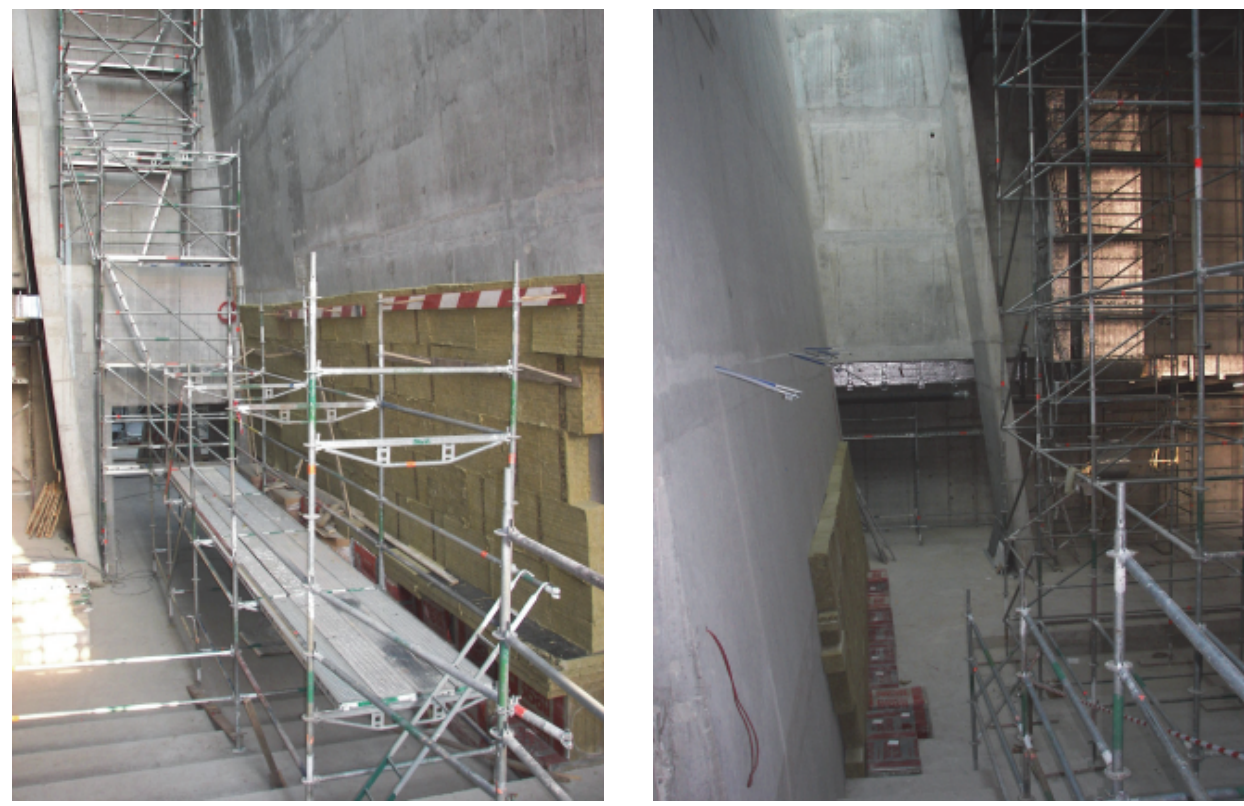

Rys. 5. Sala wielofunkcyjna w trakcie eksperymentu akustycznego, dotyczącego badania podatności sali na formowanie się echa trzepoczacego; widok z widowni na estradę, pokazane lewa i prawa ściana boczna (fot. A. Kulowski)

Fig. 5. The multi-purpose hall during the acoustic experiment regarding the susceptibility of the room to the formation of the flutter echo; view from the audience on the stage (the left and right side wall are shown (photo by A. Kulowski) 
- dt. $\times$ szer. $\times$ wys.: $30,5 \times 20,7 \times$

17,6 m, estrada: dł. $\times$ szer: 15,3 $\times 9,1 \mathrm{~m}$,

- powierzchnia: $483 \mathrm{~m}^{2}$, kubatura: $5700 \mathrm{~m}^{2}$

- liczba miejsc: 433 , powierzchnia blachy kortenowej: ok. $940 \mathrm{~m}^{2}$,

- czas pogłosu: $1,3 \mathrm{~s}(\mathrm{f}=1000 \mathrm{~Hz}$, sala pusta, rys. 7).

\section{SYNERGICZNY WPŁYW MIEJSCA PREZENTACJI NA PERCEPCJĘ DZIEKA SZTUKI}

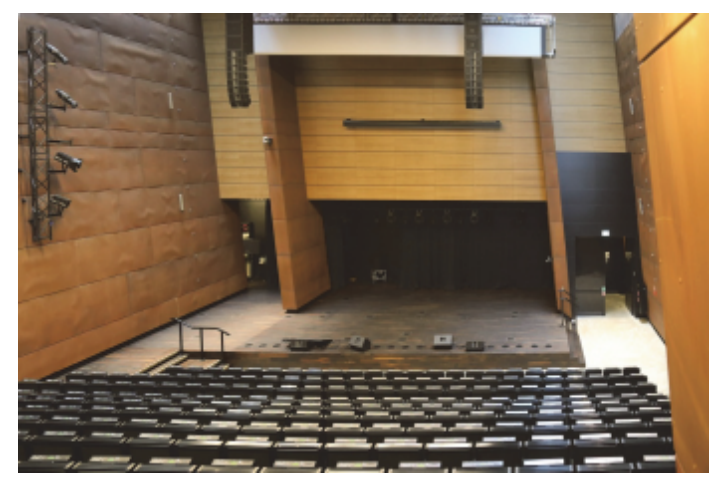

Rys. 6. Sala wielofunkcyjna, widok z widowni na scenę (fot. Wojciech Targowski)

Industrialna sceneria i wy- Fig. 6. The multi-purpose hall, view from the audience rastajaca z niej akustyka wnętrz nabiera szczególnego znaczenia w kontekście wydarzeń artystycznych prezentowanych w ECS. Jest to potwierdzeniem istotnego wpływu miejsca prezentacji sztuki na jej percepcję, znanego od poczatku istnienia sztuki i obecnego w każdym jej przejawie. Przykładem takiej synergii, wyczuwalnej niemal w każdym spotkaniu lub wydarzeniu artystycznym mającym miejsce w ECS, jest estradowe wykonanie opery "Fidelio" Ludwika van Beethovena $w$ ogrodzie zimowym 30 sierpnia 2017 roku (rys. 8). Oprócz rodzimych artystów wykonawcami koncertu byli imigranci i uchodźcy z krajów ogarniętych konfliktami on the stage (photo by Wojciech Targowski)

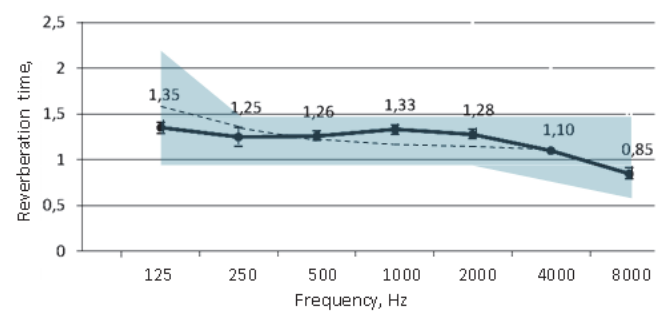

Rys. 7. Czas pogłosu sali wielofunkcyjnej, średnia z 6 punktów pomiarowych; źródło dźwięku: strzał pistoletowy; linia przerywana: czas pogłosu wg projektu akustyki; kolorem niebieskim zaznaczono zakres wartości zalecanych wg [6]

Fig. 7. Reverberation time of the multi-purpose hall, the average of 6 observation points, empty room; sound source: pistol shot; dashed line: reverberation time according to the acoustics design; the range of recommended values is marked in blue [6] [13]. Miejsce prezentacji, jakim jest ECS, nabiera szczególnej wymowy, gdy wraz z przesłaniem ideowym dzieła szłuki ma odniesienie do pozostających jeszcze w pamięci lub trwajacych wydarzeń o doniosłych skutkach społecznych, jakimi sa masowe protesty w tym właśnie miejscu w roku 1981, transformacja w Polsce w roku 1989, a także trwajacy obecnie napływ imigrantów do Europy. Sztuka staje się wówczas czytelnym nośnikiem idei solidarności, łączącej te wydarzenia.

Niezwiqzanym z ECS, wymownym przykładem synergicznego zwiq̨zku między miejscem traumatycznych wydarzeń a treścia prezentowanego dzieła jest historyczne wykonanie mszy żałobnej „Requiem” W.A. Mozarta w Sarajewie w roku 1994. Koncert odbył się w mieście będącym stolicą olimpiady zimowej w roku 1984 , zniszczonym 10 lał później podczas wojny domowej w Bośni, wśród nieuprzątniętych gruzów zrujnowanej czyłelni Biblioteki Narodowej [12]. Wykonawcami była 


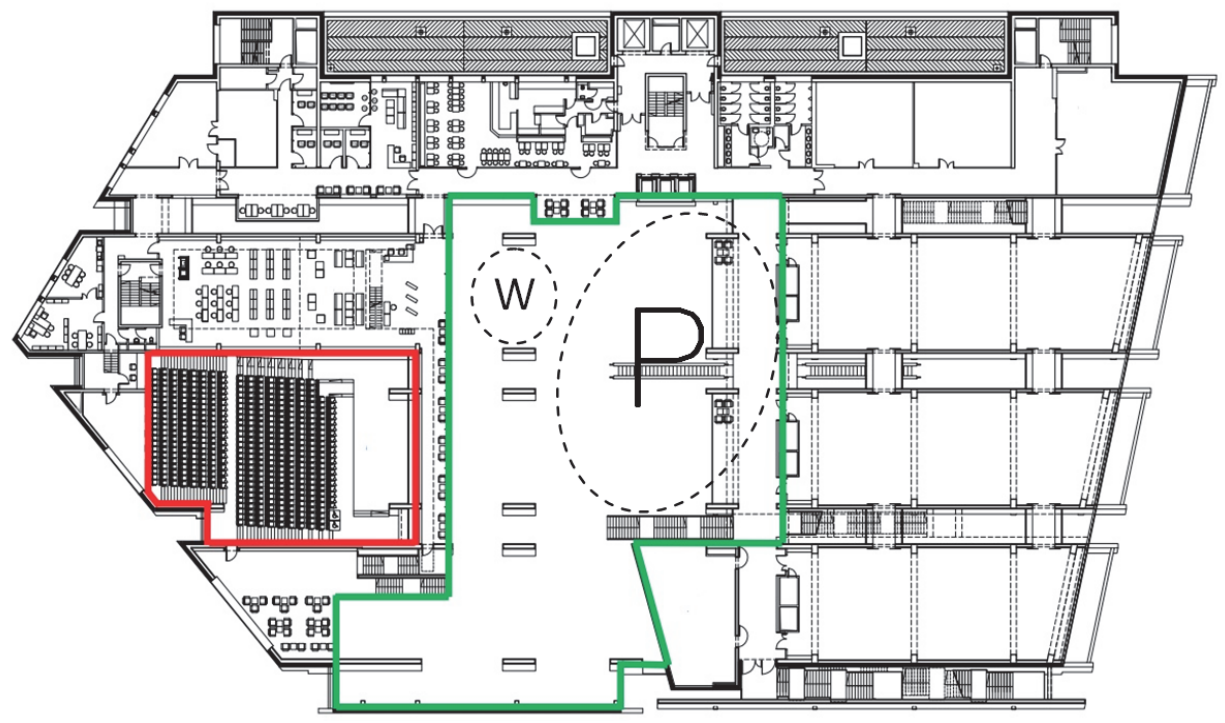

Rys. 8. Położenie sali wielofunkcyjnej i ogrodu zimowego na planie ECS; pokazane usytuowanie wykonawców (W) i publiczności (P) podczas estradowego wykonania opery "Fidelio" Ludwika van Beethovena w ogrodzie zimowym (opracowanie własne)

Fig. 8. Location of the multifunctional hall and the winter garden on the ECS plan; the positioning of the performers (W) and the audience (P) during the stage performance of Ludwig van Beethoven's opera "Fidelio" in the winter garden is shown (own study)

zdekompletowana przez wojnę orkiestra i chór miasta Sarajewo ze światowej klasy dyrygentem i solistami (Zubin Mehta, José Carreras) [16, 18].

\section{ZAKOŃCZENIE}

Architektura ECS w czytelny sposób nawiq̨zuje do architektury industrialnej. Głównymi środkami wyrazu architekłonicznego sa tu kszłałt bryły budynku, rozwiązanie wnętrz i jednolitość materiału wykończeniowego, dominującego na elewacjach i we wnętrzach. Budynek odwołuje się do formy wielkoprzemysłowego obiektu fabrycznego o wysokich ścianach z rozległymi, jednokondygnacyjnymi halami montażowymi. Całość jest wykończona pozornie nieatrakcyjna blacha kortenowa.

Głównym pomieszczeniem ECS jest ogród zimowy, kłóry wraz z pomieszczeniami towarzyszącymi zajmuje większość kubatury budynku. Konsekwentne użycie blachy jako materiału wykończeniowego w tak wysokim i rozległym wnętrzu prowadzi do dużej pogłosowości, typowej dla pomieszczeń przemysłowych. Rozczłonkowanie wnętrza, uzyskane dzięki antresolom ze schodami ruchomymi, szerokim korytarzom wnikajacym do głównej bryły, dużym zgrupowaniom roślinności oraz ustrojom dźwiękochłonnym umieszczonym w wyższych partiach pomieszczenia, pozwoliło na wytworzenie korzystnych warunków akustycznych. W obecnym stanie umożliwiaja one prowadzenie akływności o zróżnicowanych formach - od wystaw poprzez różnego typu spotkania aż po kwalifikowana działalność koncertowa. 
W publikacji wykazano, że pozornie nieefektowny wizualnie i w zasadzie akustycznie nieodpowiedni materiał wykończeniowy, jakim jest blacha kortenowa, dzięki twórczej inwencji architekła zyskuje nowy, atrakcyjny wymiar. Dzięki właściwym decyzjom architektonicznym, podkreślonym przez użycie wszechobecnej blachy kortenowej, przemysłowa tradycja miejsca i warstwa ideologiczna obiektu sa obecne w społecznym odbiorze programowej działalności ECS.

\section{LITERATURA}

[1] Cremer L., Müller H.A., Schultz T.J., 1982. Principles and application in room acoustics. Applied Science Publishers, London - New York, 1982, chap. 1.1.

[2] Egan M.D., 1988. Concepts in architectural acoustics. McGraw-Hill Book Company, New York, s. 89-90.

[3] Europäisches Solidaritätscenter Danzig, 2008. Wettbewerbe Aktuell 2, s. 39-41 (in German).

[4] Fasold W., Kraak W., Schirmer W., 1984. Taschenbuchakustik. VEB Verlag, Berlin,Teil 2, 9.3.2.3.

[5] http://sztuka-architektury.pl/article/4182/cricoteka-most-miedzy-historia-anowoczesnoscia (dostęp: 24.02.2019).

[6] Kulowski A., 2011. Akustyka sal - zalecenia projektowe dla architektów [Acoustics of halls - design recommendations for architects]. Wydawnictwo Politechniki Gdańskiej, Gdańsk.

[7] Nietupski R., 2016. European Solidarity Centre in Gdańsk. Engineering Structures of the Visegrad Countries, Jaga Group, Bratislava, s. 168-179.

[8] Puzyna Cz., 1974. Zwalczanie hałasu w przemyśle - zagadnienia wybrane [Noise Control in Industry - Selected Issues]. WNT, Warszawa, ch. 5.1.

[9] Sadowski J., 1971. Akustyka w urbanistyce, architekturze i budownictwie [Acoustics in urban planning, architecture and construction]. Arkady, Warszawa, chap. 18.2.3.

[10] Taborska H., 2016. Sztuka w otwartej przestrzeni publicznej i upamiętnianie ofiar cywilnych II wojnyświatowej - Coventry 1940-2015 [Art in open public space and commemoration of victims of the second world war - Coventry 1940-2015]. Zeszyty Naukowe Polskiego Uniwersytetu na Obczyźnie (PUNO) w Londynie, Seria trzecia, nr 4, Londyn, s. 25-38<puno.edu.pl/wp-content/ uploads/2018/07/ZN-PUNO-nr-4-2016.pdf> (dostęp: 24.02.2019).

[11] Targowski M., 2018. Fasady Europejskiego Centrum Solidarności - architektoniczny obraz tożsamości miejsca [Façades of the European Solidarity Center an architectural image of the place's identity]. [W:] Historia Stoczni Gdańskiej, K. Knoch et al. (red.), Europejskie Centrum Solidarności, Gdańsk, s. 641-660.

[12] Targowski W., 2018. Gmach Europejskiego Centrum Solidarności - geneza przestrzeni, w poszukiwaniu tożsamości miejsca [The building of the European Solidarity Center -the genesis of space in search of the identity of the place]. [W:] Historia Stoczni Gdańskiej, K. Knoch et al., Europejskie Centrum Solidarności, Gdańsk, s. 661-679.

[13] <trojmiasto.tv/Uchodzcy-i-imigranci-zagrali-w-operze-Fidelio-w-ECS-23454. html> (Refugees-and immigrants-they played-in-the-opera-Fidelio-in-ECS - in Polish) (dostęp: 24.02.2019). 
[14] Wojtkiewicz S., 2018. Teoretyczne aspekty praktyki w architekturze krajobrazu na przykładzie koncepcji projektowej "Alei Niezłomnych" w parku Konstyłucji 3-go maja w Białymstoku [Theoretical aspects of design practice in landscape architecture, the case of the concept design of the "Unbroken Avenue" in the 3rd may Constitution park in Bialystok]. Teka Komisji Urbanistyki i Architektury PAN Oddział w Krakowie, Urbanity and Architecture Files, †.XLVI, Kraków2018, s.449-458, <teka.pk.edu.pl/wp-content/uploads/2019/01/ Teka-2018-29.pdf>(dostęp: 24.02.2019).

[15] <www.academia.edu/5163829/_Ci\%C4\%99\%C5\%BCar_do\%C5\%9Bwiadczenia_i_pr\%C3\%B3\%C5\%BCnia_przestrzeni_miejskiej_-_Tilted_Arc_Richarda_Serry> (dostęp: 24.02.2019).

[16] www.imdb.com/title/tt0209158/ (dostęp: 24.02.2019).

[17] www.nssmc.com/product/catalog_download/pdf/A006en.pdf (dostęp: 24.02.2019).

[18] www.youtube.com/watch?v=KfTE_lwTrtQ(dostęp: 24.02.2019).

\title{
AKUSTYCZNY ASPEKT ZASTOSOWANIA BLACHY KORTENOWEJ W EUROPEJSKIM CENTRUM SOLIDARNOŚCI W GDAŃSKU
}

\begin{abstract}
STRESZCZENIE. W publikacji przedstawiono użycie blachy kortenowej jako dominujacego materiału wykończeniowego na elewacjach i we wnętrzach budynku o przesłaniu symbolicznym. Przedstawiono architektoniczne przesłanki uzasadniajace jednorodność zastosowanego materiału. Na łym tle omówiono wpływ blachy kortenowej na akustykę pomieszczeń wraz z podaniem kroków zaradczych redukujących nadmierna pogłosowość i zwiększajacych stopień rozproszenia dźwięku. Pozyływnym sprawdzianem dla warunków akustycznych uzyskanych w największym pomieszczeniu ECS jest zaprezentowanie w nim dużego dzieła z dziedziny muzyki klasycznej.
\end{abstract}

Słowa kluczowe: budowle symboliczne, płyły kortenowe, pochylone ściany, ogród zimowy, akustyka pomieszczeń, czas pogłosu, echo trzepocząe

\section{ACOUSTIC ASPECT OF APPLICATION OF CORTEN CLADDING IN EUROPEAN SOLIDARITY CENTRE IN GDAŃSK}

SUMMARY. The article describes the use of corten plates as the dominant finishing material on façades and inside the building with a symbolic message. The impact of mass use of corten cladding on room acoustics is analyzed. Remedies are presented to reduce excessive reverberation and increase the degree of sound dispersion, taking into account the form of the interior, the arrangement of finishing materials and the mass use of greenery in the winter garden, which is the largest room in the building. A positive test of the acoustic conditions was the public presentation of a large piece of classical music.

Key words: symbolic building, corten plates, tilted walls, winter garden, room acoustics, reverberation time, flutter echo 